\title{
Comparative Analysis of Three Tank Process using Soft Computing Techniques
}

\author{
P Srinivas $^{1}$ \& K Vijaya Lakshmi ${ }^{2}$ \\ Associate Professor, Department of EIE, V R Siddhartha Engineering College, Vijayawada, India ${ }^{1}$ \\ Assistant Professor, Department of EIE, V R Siddhartha Engineering College, Vijayawada, India ${ }^{2}$
}

\begin{abstract}
Most of the process systems exhibits non-linear behaviour, so conventional controllers are not able to provide accurate data. At present, various soft computing techniques are used to overcome imprecision and uncertainty effects of conventional controllers. Various soft computing techniques like fuzzy logic, genetic algorithm and particle swarm optimization have been suggested for optimum setting of PID controller parameters. In this paper, the performance of all the three soft computing techniques is compared for three tank level process control system. This comparative study is carried out for set point tracking of three tank level process using MATLAB/ SIMULINK. The simulation results shows that tuning the PID controller using PSO provides fast and stable system with low overshoot.
\end{abstract}

Keywords: Three tank process, Soft computing, Fuzzy logic, Genetic algorithm, Particle swarm optimization.

\section{INTRODUCTION}

Most of the real time and industrial processes are controlled using PID (proportional-integral-derivative) controllers. Due to their better performance in a wide range of operating conditions and functional simplicity, PID controllers are most widely used in the process control industries (Pillay and Govender, 2007). In spite of its widespread use, one of its limitations is that there is no effective tuning method for this type of controller (Åström and Hägglund, 1995).Several methods have been proposed for the tuning of PID controllers. At present the ZieglerNichols method (Ogata, 1987) may be the most well known conventional technique for tuning of PID controller. For a wide range of practical processes, this tuning approach works quite well. However, sometimes it does not provide better tuning and produce a large peak overshoot. Therefore, this method usually needs retuning before applied to control industrial processes. To enhance the capabilities of conventional PID tuning techniques, soft computing techniques have been introduced. With the advance of computational methods in the recent times, optimization algorithms are often proposed to tune the control parameters in order to find an optimal performance (Gaing,2004; Solihin, et al 2011).

Rapid growth in soft computing techniques has marked new milestones in powerful representation, modelling paradigms and optimization mechanisms for solving modern controller issues. Soft Computing is the fusion of methodologies that were designed to model and enable solutions to real world problems, which are too difficult to model, mathematically. Soft computing is a consortium of methodologies that works synergistically and provides, in one form or another, flexible information processing capability for handling real-life ambiguous situations [1][2]. Its aim is to exploit the tolerance for imprecision, uncertainty, approximate reasoning and partial truth in order to achieve robustness and low-cost solutions [3].
The guiding principle is to devise methods of computation that lead to an acceptable solution at low cost, by seeking for an approximate solution to an imprecisely or precisely formulated problem [4].The principal constituents of soft computing include theory of neurons, fuzzy logic, evolutionary computing, genetic algorithms, and probabilistic reasoning. Out of which the three emerging techniques viz. fuzzy logic, genetic algorithms and particle swam optimisation are considered in this paper to control the process of the systems.

Fuzzy logic is a universal approximate of any multivariate function because it can be used for modelling highly nonlinear, unknown or partially known controllers, plants or processes[5][6]. It emulates human reasoning and provides an intuitive way to design functional block for an intelligent control system. Genetic algorithms (GAs) have emerged as potentially robust optimization tools in the last decades. Genetic algorithms (GAs) are a search heuristic that mimics the process of natural evolution. Genetic algorithms (GAs) can be applied to the process controllers for their optimization using natural operators viz. mutation and crossover [7]. Although GAs provides good solution but they do not keep information about the best solution in the whole community. This strategy extends search by the introduction of memory and development of particle swarm optimization (PSO) by Kennedy and Eberhart [8]. In optimization, along with the local best solution, a global best solution is also stored somewhere in the memory, so that all particles not trapped into local optima but moves to global optima.

This paper attempts to simulate automatic PID tuning scheme using three soft computing schemes like fuzzy logic, Genetic and PSO algorithms for three tank level process. The simulation of soft computing techniques is performed using MATLAB/ SIMULINK. Then the simulation results are compared to determine the best soft computing technique for tuning of the PID controller. 
THREE TANK SYSTEM MODEL

Most widely used industrial three tank level process is shown in Fig.1 [9]. Here q: inflow of liquid; $\mathrm{q}_{0}$. outflow of liquid; h1, h2, h3: height of liquid in three tanks respectively; A1, A2, A3: cross section area of three tanks respectively.

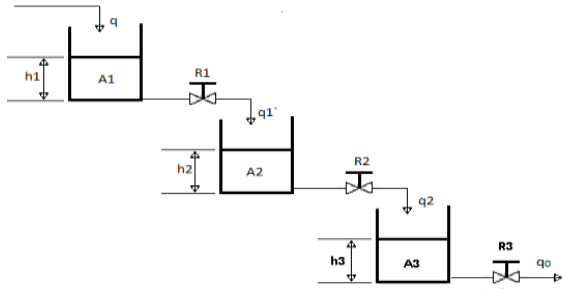

Fig.1 Three Tank Level Control System

For tank-1:

$\mathrm{q}-\mathrm{q}_{1}=\mathrm{A}_{1}\left(\mathrm{dh}_{1} / \mathrm{dt}\right)$

For tank-2:

$\mathrm{q}_{1}-\mathrm{q}_{2}=\mathrm{A}_{2}\left(\mathrm{dh}_{2} / \mathrm{dt}\right)$

For tank-3:

$\mathrm{q}_{2}-\mathrm{q}_{0}=\mathrm{A}_{3}\left(\mathrm{dh}_{3} / \mathrm{dt}\right)$

Where

$\mathrm{q}_{1}=\mathrm{h}_{1} / \mathrm{R}_{1} ; \mathrm{q}_{2}=\mathrm{h}_{2} / \mathrm{R}_{2} ; \mathrm{q}_{0}=\mathrm{h}_{3} / \mathrm{R}_{3}$

and $\mathrm{T}_{1=} \mathrm{A}_{1} \mathrm{R}_{1} ; \mathrm{T}_{2}=\mathrm{A}_{2} \mathrm{R}_{2} ; \mathrm{T}_{3}=\mathrm{A}_{3} \mathrm{R}_{3}$

Therefore, the transfer function of the above three tank system is

$\mathrm{G}(\mathrm{s})=\mathrm{Q}_{0}(\mathrm{~s}) / \mathrm{Q}(\mathrm{s})=1 /\left(1+\mathrm{T}_{1} \mathrm{~s}\right)\left(1+\mathrm{T}_{2} \mathrm{~s}\right)\left(1+\mathrm{T}_{3} \mathrm{~s}\right)$

By considering $\mathrm{T} 1=1 \mathrm{sec}$., $\mathrm{T} 2=0.5 \mathrm{sec}$. and $\mathrm{T}_{3}=0.33 \mathrm{sec}$. The overall transfer function of the three tank system is represented as

$$
\mathrm{G}(\mathrm{s})=6 /(\mathrm{s}+1)(\mathrm{s}+2)(\mathrm{s}+3)
$$

\section{SOFT COMPUTING TECHNIQUES}

\section{A. FUZZY LOGIC CONTROL}

Fuzzification, fuzzy rule base and defuzzification are the three basic steps used in Fuzzy logic controller. The development of fuzzy controller is given clearly based on the earlier approaches in the fuzzy related research [10].

\section{Fuzzification:}

The fuzzification process converts crisp values of inputs and outputs into linguistic variables. We have defined two inputs (error and feedback signal) and one output (controller output) for this application. FIS editor for three tank process is shown in figure 2.Based on the controller output we estimated the system response [11].

\section{Fuzzy rule base:}

The fuzzy rules represent the level of knowledge and abilities of human who adjusts the system for minimum error and fast response. Rule base is composed of IFClause and THEN- clause [12].

\section{Defuzzification:}

This process converts the estimated linguistic output based on fuzzy rules into crisp value. In this paper, centroid defuzzification method is applied to the process [13].

\section{B. GENETIC ALGORITHM}

Fig.2 FIS editor for Three Tank Level Control System

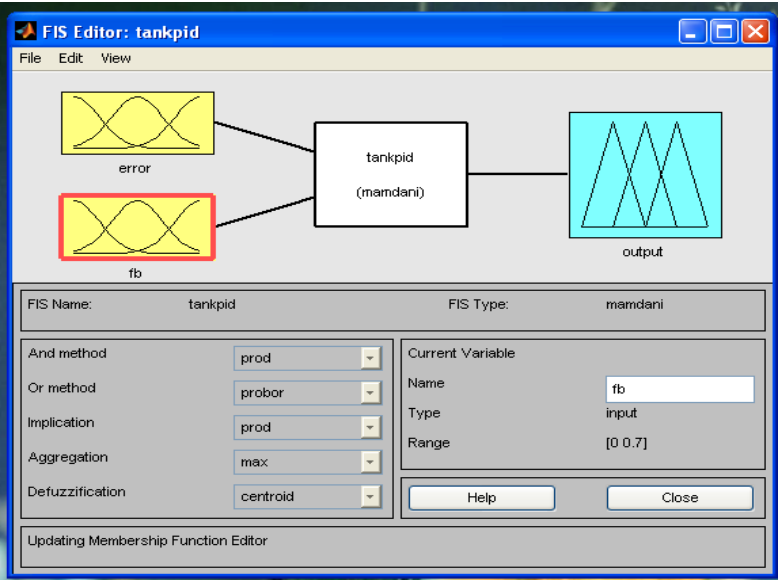

Genetic Algorithm (GA) is the stochastic global search optimization technique based on the process of natural evolution. Difficult search and optimization problems are quickly and reliably solved by GA which is an effective and efficient algorithm. Selection, crossover and mutation are three major operators and population size, selection, crossover and mutation rate are four control parameters in GA [14].

\section{Reproduction}

The fitness value of each chromosome is assessed in the reproduction phase. To provide bias towards fitter individuals the selection process is continued with this fitness value. Commonly used methods for selection are Roulette Wheel selection, Stochastic Universal sampling Normalized geometric selection and Tournament selection.

\section{Crossover:}

After the completion of selection process, the crossover algorithm is initiated. To capture the better parts of old chromosomes and create new best one the crossover operation swaps certain parts of the two selected strings in a bid. With the help of any one of four encoding schemes like binary encoding, permutation encoding, value encoding and tree encoding, crossover can be performed.

3. Mutation :

A process by which the chance for the GA to reach the optimal point is reinforced through just an occasional alteration of a value at a randomly selected bit position is called Mutation. The mutation process may quickly generate those strings which might not be conveniently produced by the previous reproduction and crossover processes. 


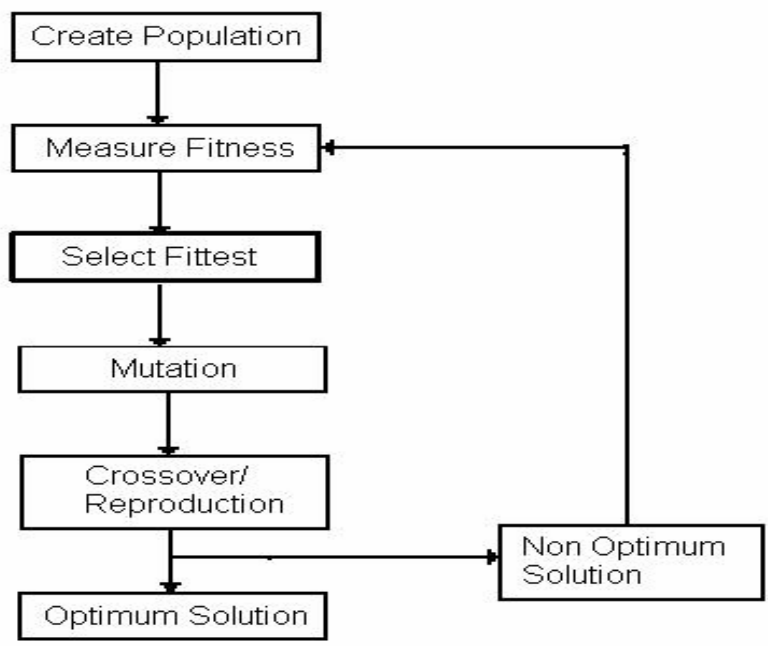

Fig.3 Flowchart of GA

The sequence of operations performed in GA are represented in flowchart is shown in fig.3.Genetic algorithms (GAs) start with solutions set represented by chromosomes, called population. Solutions from one population are chosen and used to build a new population, which is motivated by the possibility that the new population will be better than the old one. Further, solutions are selected based on their fitness to build new solutions, that is, off springs. The above process is repeated until some condition is satisfied. The essential steps in implementing a GA are

1. Initialization of Population.

2. Setting the GA Parameters.

3. Performing the GA

The GA starts with the initialization of the population size, variable bounds and the evaluation function.

4. Objective Function of the Genetic Algorithm

The most important part of building a GA is writing the objective function. In this process, the objective function is required to choose the best PID controller for the process. An objective function is developed to find a PID controller that produces minimum overshoot, quick rise time or optimal settling time. In order to combine all these objectives, we developed an objective function that optimizes the error of the process control system. Each chromosome in the population is passed into the objective function at every iteration. Then the chromosome is evaluated and assigned a number to represent its fitness, the bigger its number the better its fitness [15]. The GA utilizes the fitness value of chromosome's to generate a new population consisting of the fittest members.

\section{PARTICLE SWARM OPTIMIZATION}

Particle swarm optimization (PSO) is a global optimization algorithm for solving the problems in which a best solution can be represented as a point or surface in an n-dimensional space. Hypotheses are plotted in this space and seeded with an initial velocity, as well as a communication channel between the particles. Particles then move through the solution space, and are evaluated based on some fitness criterion after every time step. Over time, particles are accelerated towards those particles within their communication grouping which have better fitness values. The merit of such an approach over other global minimization techniques such as simulated annealing is that the large numbers of members that make up the particle swarm make the technique impressively resilient to local minima problem.

1. PSO Algorithm :

1) Initialize the swarm by randomly assigning every particle to an arbitrarily initial velocity and a position in every dimension of the solution space.

2) Compute the selected fitness function to be optimized for each particles position.

3) For each individual particle, update its historically best position so far, $\mathrm{P}_{\mathrm{i}}$ if its current position is better than its historically best one.

4) Identify/Update the swarm's globally best particle that has the swarm's best fitness value, and set/reset its index as $\mathrm{g}$ and its position at $\mathrm{P}_{\mathrm{g}}$.

5) Update the velocities of all the particles using equation.

$$
\begin{aligned}
& \mathrm{V}_{\mathrm{id}}^{(\mathrm{t}+1)}=\omega \mathrm{V}_{\mathrm{id}}^{\mathrm{t}}+\mathrm{C}_{1} \mathrm{R}_{1}\left(\mathrm{P}_{\mathrm{id}}^{\mathrm{t}}-\mathrm{X}_{\mathrm{id}}^{\mathrm{t}}\right)+ \\
& \mathrm{C}_{2} \mathrm{R}_{2}\left(\mathrm{P}_{\text {gd }}^{\mathrm{t}}-\mathrm{X}_{\mathrm{id}}^{\mathrm{t}}\right)
\end{aligned}
$$

6) Move each particle to its new position using equation.

$$
\mathrm{X}_{\mathrm{id}}^{(\mathrm{t}+1)}=\mathrm{X}_{\mathrm{id}}^{\mathrm{t}}+\mathrm{V}_{\mathrm{id}}^{(\mathrm{t}+1)}
$$

7) Repeat steps 2-6 until convergence or a stopping criterion is met (e.g., the maximum number of allowed iterations is reached, a sufficiently good fitness value is obtained or the algorithm has not give better performance).

\section{Concept of Fitness Function:}

For the design of PID controller for three tank process, we had to tune all the three parameters of PID such that it gives the best output results. Here we define a three dimensional search space in which all the three dimensions define three tuning parameters of the PID controller. Each particular point in the search space represent one set of [KP KI KD] for which a particular response is obtained .The performance of the point or the set of PID parameters is evaluated by a fitness function or the cost function. This cost function consists of several component functions which are the performance index of the design [16].

For this design, we have considered four component functions to define fitness function. The fitness function is a function of steady state error, peak overshoot, rise time and settling time. However the contribution of these component functions towards the original fitness function is determined by a scale factor that depends upon the choice of the designer. For this design the optimum point is the point where the fitness function has the minimal value.

The chosen fitness function is

$F=(1-\exp (-\beta))\left(M_{P}+E_{S S}\right)+(\exp (-\beta))\left(T_{S}-T_{R}\right)$ 
Where F:- Fitness function

$\mathrm{M}_{\mathrm{P}}$ :- Peak Overshoot

$\mathrm{T}_{\mathrm{S}}$ :- Settling Time

$\mathrm{T}_{\mathrm{R}}$ :- Rise Time

$\beta$ :-Scaling Factor (Depends upon the choice of designer) In our design we have chosen the scaling factor $\beta=0.5$.In the Matlab library we have defined a fitness function which has PID parameters as input values and it returns the fitness value of the PID based controlled model as its output. It has the format Function $[\mathrm{F}]=$ fitness $(\mathrm{KD} \mathrm{KP}$ $\mathrm{KI})$

3. PSO Selection Parameters:

To start up with PSO, some parameters are to be defined. Selection of these parameters decides to a great extent the ability of global minimization. The maximum velocity affects the ability of escaping from local optimization and refining global optimization. The size of swarm balances the requirement of global optimization and computational cost. Initializing the values of the parameters is as per Table 1.

Table 1: Parameters of PSO

\begin{tabular}{|l|l|}
\hline Population size & 100 \\
\hline Number of iterations & 100 \\
\hline Velocity constant c1 & 0.12 \\
\hline Velocity constant c2 & 2 \\
\hline
\end{tabular}

In this method, each particle contains three members $\mathrm{P}, \mathrm{I}$ and $\mathrm{D}$ (three dimensional search space) and the particles must fly in a three dimensional space to find the optimal tuning parameters [17].

\section{SIMULATION RESULTS}

\section{A. FUZZY LOGIC CONTROL}

The simulink model of three tank system with fuzzy controller is shown in Fig. 4.

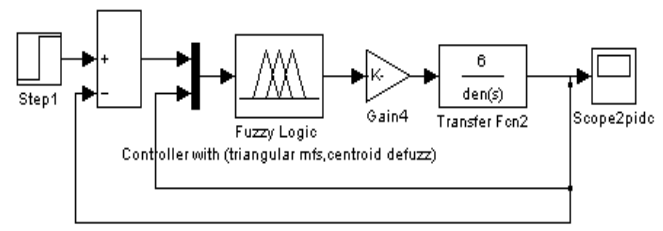

Fig.4 Process model with fuzzy logic controller The unit step response of the three tank system using fuzzy logic controller with centroid defuzzification and triangular fuzzification is shown in Fig.5.With the use of a FLC, the overshoot is removed and rise-time and settling time are reduced significantly when compared with conventional PID controller.

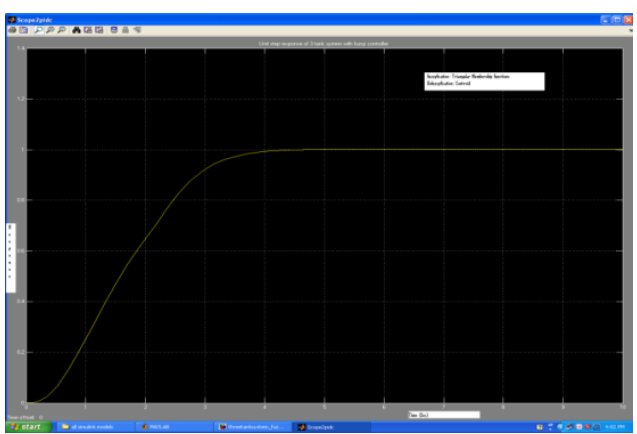

Fig.5 Response with triangular fuzzification

\section{B. GA-PID CONTROLLER}

The MATLAB program for GA based PID controller tuning with ISE criteria is implemented and simulated. Then the unit step response of three tank process is plotted. The variation of tuning parameters $\left(\mathrm{K}_{\mathrm{P}}, \mathrm{K}_{\mathrm{I}}\right.$ and $\left.\mathrm{K}_{\mathrm{D}}\right)$ of genetic algorithm based PID controller for ISE criteria is plotted in Fig.6 and the corresponding unit step response of three tank process is plotted in Fig.7.

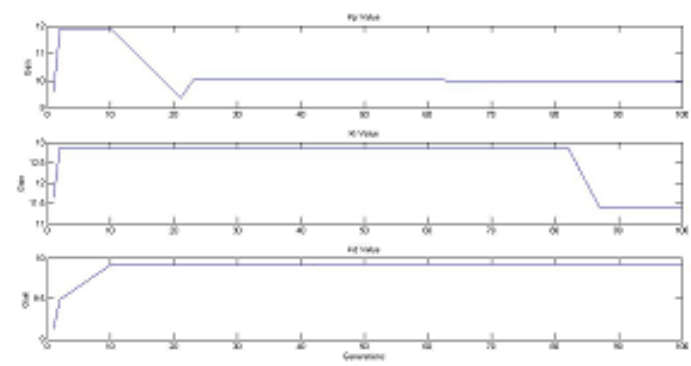

Fig.6 Variation of tuning parameters of genetic algorithm based PID controller for ISE Criteria

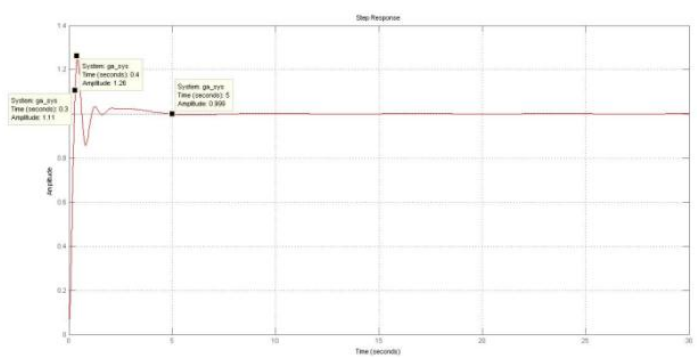

Fig.7 Unit step response of three tank system with genetic algorithm based PID controller for ISE criteria

The observed time domain specifications from the response graph are tabulated in Table 2.

Table 2: Time domain specifications for ISE criteria

\begin{tabular}{|l|c|}
\hline $\begin{array}{l}\text { Time domain } \\
\text { specifications }\end{array}$ & $\begin{array}{c}\text { GA based } \\
\text { PID controller }\end{array}$ \\
\hline Rise time, sec & 0.30 \\
\hline Peak time, sec & 0.40 \\
\hline Settling time, sec & 5.00 \\
\hline Peak overshoot & 1.26 \\
\hline
\end{tabular}




\section{PSO-PID CONTROLLER}

The PSO based PID controller for the three tank level control system is implemented using MATLAB software. $\mathrm{K}_{\mathrm{p}}, \mathrm{K}_{\mathrm{i}}$ and $\mathrm{K}_{\mathrm{d}}$ are considered as three dimensional search space in this process. The fitness function is selected based on time domain characteristics for adaptation. The number of adaptation iterations is decided based on expected parameters and time of computation. Variation of $\mathrm{K}_{\mathrm{p}}, \mathrm{K}_{\mathrm{i}}$ and $K_{d}$ for desired number of iterations and the unit step response of system are shown in Fig.8 and Fig.9 respectively.

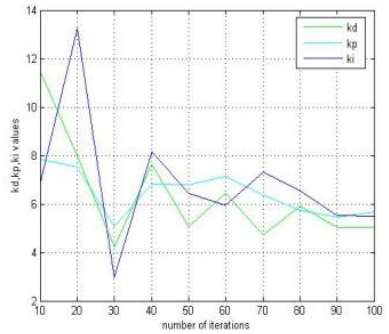

Fig.8 The results of $K_{D}, K_{P} \& K_{I}$ over the iterations

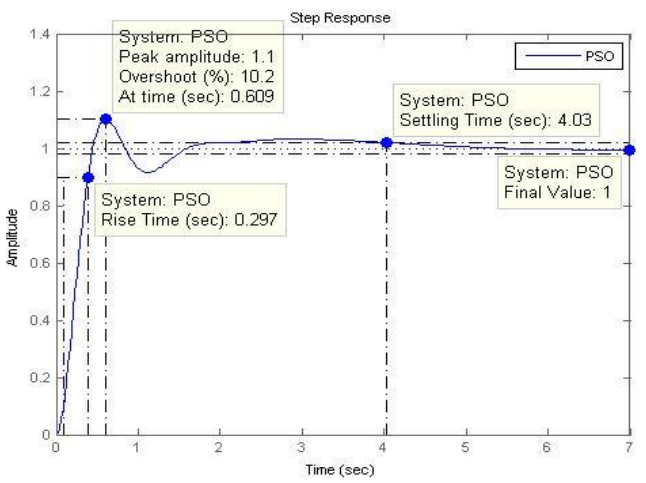

Fig.9 Response of the system using PSO-PID Controller

\section{COMPARISON OF UNIT STEP RESPONSE USING SOFT COMPUTING TECHNIQUES}

The performance indices of three tank process in terms of time domain specifications using various soft computing techniques are tabulated in Table 3.

Table 3: Comparison of performance indices using soft computing techniques

\begin{tabular}{|l|c|c|c|}
\hline \multirow{2}{*}{$\begin{array}{l}\text { Time domain } \\
\text { specifications } \\
\text { or Performance } \\
\text { indices }\end{array}$} & \multicolumn{3}{|c|}{ Soft computing techniques } \\
\cline { 2 - 4 } & $\begin{array}{c}\text { Fuzzy } \\
\text { Logic } \\
\text { (FLC } \\
\text { ) }\end{array}$ & $\begin{array}{c}\text { Genetic } \\
\text { Algorith } \\
\mathrm{m}\end{array}$ & $\begin{array}{c}\text { Particle } \\
\text { swam } \\
\text { optimizatio } \\
\text { (GA) }\end{array}$ \\
\hline Rise time, sec & 2.8 & 0.30 & 0.297 \\
\hline Peak time, sec & 2.8 & 0.40 & 0.609 \\
\hline $\begin{array}{l}\text { Settling time, } \\
\text { sec }\end{array}$ & 4.6 & 5.00 & 4.03 \\
\hline Peak overshoot & 0 & 1.26 & 1.1 \\
\hline
\end{tabular}

PSO-PID controller shows superiority in terms of settling time over other computing techniques for three tank level process. Fuzzy logic controller shows better response compared to genetic algorithm and produces zero overshoot. Genetic algorithm produces less peak time over PSO based PID algorithm.

\section{CONCLUSION}

Research has been carried out to get an optimal tuning of PID controller by using soft computing techniques. In this paper, we developed the three tank system mathematical model and simulated with fuzzy logic controller, GA based controller and PSO based PID controller using Matlab/Simulink. From the analysis we conclude that three tank system with PSO based PID controller gives minimum settling time for unit step input. Fuzzy controller gives optimum rise time and peak time with zero peak overshoot. For this application either fuzzy controller or PSO based PID controller produces optimum response compared to GA based controller. This analysis is useful especially for optimum level control in industries like food processing, petro chemical industries.

\section{REFERENCES}

[1] Lotfi A. Zadeh (1994), "Fuzzy Logic, Neural Networks and Soft Computing", Communication of the ACM, 37(3), pp77-84

2] N. L. Schneider, S. Narayanan, and C. Patel (2000), "Integrating genetic algorithms and interactive simulations for airbase logistics planning," in Soft Computing in Industrial Applications,Y. Suzuki, S.Ovaska, T. Furuhashi, R. Roy, and Y. Dote, Eds. London, U.K.: Springer- Verlag, pp. 309-317.

[3] Aliev R. (2001). Soft Computing and its Applications. Azerbaidjan Oil Academy. Baku.2001.

[4] Nagraj B., Subha S. and Rampriya B., (2008), "Tuning Algorithm for PID controller using soft computing Techniques," International Journal of Computer Science and network Security, 8(4), pp. 278281.

[5] Berenji, H.R. (1992). Fuzzy Logic Controllers. In R.R.Yager, L.A. Zadeh (eds.) An Introduction to Fuzzy Logic Applications and Intelligent Systems. Kluwer Academic Publisher, Boston, MA, Chapter 4.

[6] Zadeh, Lotfi. A. (1994). Soft Computing and Fuzzy Logic. IEEESoftware, vol. 11, no. 6,48-56.

[7] Chang Wook Ahn and Ramakrishna, R.S., (2002), "A genetic algorithm for shortest path routing problem and the sizing of populations," IEEE Transactions on Evolutionary Computation, 6(6), pp. 566-579.

[8] P.Aravind and Dr.S.M.Giriraj Kumar, "Optimal Tuning of PI Controller using Swarm Intelligence for a Nonlinear Process", International Journal of Advanced Research in Electrical, Electronics and Instrumentation Engineering, Vol.2, Issue 12, December 2013.

[9] P.Srinivas and P.Durga Prasada Rao, "Comparitive Analysis of Conventional PID Controller and Fuzzy Controller with various Defuzzification Methods in a Three Tank Level Control System", International Journal of Information technology, Control and Automation, Vol. 2, No. 4, October 2012.

[10] Surachai Panich, 'Development of Fuzzy Controller for Water Level in Stream Boiler Tank', Journal of Computer Science 6 (11): 1233-1236, 2010

[11] Zadeh, L. A., 'Is there a need for fuzzy logic?', Information Sciences: an International Journal,178(13):2751-2779, 2008.

[12] S.R.Vaishnav \& Z.J.Khan, 'Design and Performance of PID and Fuzzy Logic Controller with Smaller Rule Set for Higher Order System, Proceedings of the World Congress on Engineering and Computer Science 2007, October 24-26, 2007, San Francisco, USA.

[13] Ismail H.Altas \& Adel M.Sharaf, 'A generalized approach for designing fuzzy logic controllers in matlab/simulink GUI 
INTERNATIONAL JOURNAL OF INNOVATIVE RESEARCH IN ELECTRICAL, ELECTRONICS, INSTRUMENTATION AND CONTROL ENGINEERING Vol. 3, Issue 5, May 2015

environment' International journal of information technology \& intelligent computing ,no. 4 ,Vol.1,2007.

[14] D.E. Goldberg, Genetic Algorithms in Search, Optimization, and Machine Learning, Addison-Wesley Publishing Co., Inc., 1989.

[15] Y. J. CAO and Q. H. WU, Bristol, Teaching Genetic Algorithm Using Matlab, Int. J.Elect. Engineering. Educ., Vol. 36, pp. 139153. Manchester U.P., 1999. NCSU-IE TR 95-09, 1995.

[16] Nekoui M.A, Khameneh M.A and Kazemi M.H, "Optimal Design of PID Controller for a CSTR System using Particle Swarm Optimization", Power Electronics and Motion Control Conference, Page(s): T7-63 - T7-66, 2010.

[17] Sulochana Wadhwani and Veena Verma, "Evolutionary Computation Techniques Based Optimal PID Controller Tuning", International Journal of Engineering Trends and Technology, Volume 4, Issue 6, June 2013. 